\title{
Información básica sobre recursos y servicios del Sistema Nacional de Salud*
}

$\mathrm{N}$ uevamente, la Dirección General de Estadística e Informática da a conocer la serie de nueve tabulados que incluyen la información más relevante generada durante 1997 por las instituciones que integran el Sistema Nacional de Salud. Las variables que conforman el contenido de los cuadros se presentan en su dimensión nacional, por institución y por entidad federativa; éstos fueron integrados a partir de las cifras absolutas y sus respectivos indicadores, de tal manera que se proporciona la información más relevante y completa sobre el tema. Las categorías analizadas corresponden, tanto a los recursos físicos, materiales y humanos, como a los servicios de atención que otorgan anualmente las diversas instituciones del país.
Resulta de gran importancia dar a conocer esta información, ya que puede llegar a constituirse en un valioso apoyo para la elaboración de diversos diagnósticos sobre la salud pública en México y para una adecuada toma de decisiones en el área.

Por último, cabe destacar que, sólo teniendo un conocimiento integral de la capacidad de cobertura y de los servicios otorgados por las instituciones, se podrán ampliar los programas y actividades relacionados con la atención a la salud, a fin de que codyuven a satisfacer las necesidades y demandas de la población.

Para obtener mayor detalle de la información aquí presentada, se pueden consultar las publicaciones de la Dirección General de Estadística e Informática, especialmente el
Boletin de Informacion Estadistica, núm. 17, vols. I y III, correspondientes a 1997, y la publicación Cifras municipales en salud. Bases de informacion, 1997. La consulta se puede hacer en el Centro de Referencia e Información Estadística en Salud, ubicado en Leibnitz 20, 5o. piso, colonia Nueva Anzures, 11590 México, D.F., o bien, en Internet, en la página electrónica de la Secretaría de Salud, cuya dirección es http://www.ssa.gob.mx, eligiendo el menú de Unidades Administrativas (Dirección General de Estadística e Informática) o el de Estadísticas del Sistema Sectorial de Información.

* Sección preparada por la Dirección General de Estadística e Informática de la Secretaría de Salud, México. 


\section{Cuadro I \\ Principales Recursos físicos y materiales por entidad federativa. Sistema Nacional de Salud, México, 1997}

\begin{tabular}{|c|c|c|c|c|c|c|c|c|c|c|}
\hline \multirow[b]{2}{*}{ Entidad federativa } & \multicolumn{3}{|c|}{ Unidades de salud } & \multicolumn{2}{|c|}{ Camas } & \multirow[b]{2}{*}{$\begin{array}{l}\text { Consul- } \\
\text { torios }\end{array}$} & \multirow[b]{2}{*}{$\begin{array}{l}\text { Quiró- } \\
\text { fanos }\end{array}$} & \multirow[b]{2}{*}{$\begin{array}{l}\text { Salas de } \\
\text { expulsión }\end{array}$} & \multirow[b]{2}{*}{$\begin{array}{l}\text { Labora- } \\
\text { torios* }\end{array}$} & \multirow[b]{2}{*}{$\begin{array}{c}\text { Rayos } \\
x^{\ddagger}\end{array}$} \\
\hline & Total & $\begin{array}{l}\text { Consulta } \\
\text { externa }\end{array}$ & $\begin{array}{l}\text { Hospi- } \\
\text { tales }\end{array}$ & $\begin{array}{l}\text { Censa- } \\
\text { bles }\end{array}$ & $\begin{array}{c}\text { No } \\
\text { censables }\end{array}$ & & & & & \\
\hline$N$ acional & 17109 & 16194 & 915 & 76214 & 59068 & 47523 & 2599 & 6118 & 1675 & 1886 \\
\hline A guascalientes & 109 & 99 & 10 & 811 & 496 & 421 & 28 & 56 & 12 & 18 \\
\hline Baja C alifornia & 198 & 180 & 18 & 1505 & 756 & 829 & 59 & 66 & 27 & 37 \\
\hline Baja C alifornia Sur & 163 & 145 & 18 & 585 & 421 & 342 & 27 & 48 & 24 & 23 \\
\hline Campeche & 227 & 212 & 15 & 594 & 558 & 454 & 27 & 56 & 22 & 22 \\
\hline Coahuila & 374 & 333 & 41 & 2479 & 1400 & 1330 & 90 & 98 & 55 & 61 \\
\hline Colima & 145 & 135 & 10 & 466 & 568 & 364 & 15 & 69 & 14 & 16 \\
\hline Chiapas & 993 & 960 & 33 & 1621 & 2307 & 1961 & 70 & 169 & 56 & 54 \\
\hline Chihuahua & 532 & 500 & 32 & 2187 & 1578 & 1291 & 70 & 144 & 53 & 52 \\
\hline Distrito Federal & 789 & 678 & 111 & 16825 & 6223 & 7458 & 542 & 113 & 265 & 452 \\
\hline Durango & 432 & 416 & 16 & 1176 & 1409 & 855 & 36 & 114 & 32 & 27 \\
\hline Guanajuato & 556 & 528 & 28 & 2635 & 2583 & 1456 & 82 & 354 & 44 & 60 \\
\hline Guerrero & 869 & 843 & 26 & 1433 & 2404 & 1563 & 58 & 560 & 66 & 47 \\
\hline Hidalgo & 698 & 678 & 20 & 1304 & 1827 & 1121 & 32 & 337 & 38 & 21 \\
\hline Jalisco & 925 & 881 & 44 & 5928 & 4047 & 2839 & 197 & 497 & 94 & 113 \\
\hline México & 1173 & 1117 & 56 & 6886 & 4600 & 4260 & 165 & 400 & 126 & 133 \\
\hline Michoacán & 781 & 742 & 39 & 1981 & 2802 & 1620 & 78 & 224 & 56 & 51 \\
\hline Morelos & 267 & 255 & 12 & 798 & 952 & 633 & 31 & 125 & 21 & 19 \\
\hline N ayarit & 315 & 303 & 12 & 672 & 880 & 596 & 30 & 111 & 24 & 17 \\
\hline Nuevo León & 542 & 513 & 29 & 3693 & 1945 & 2037 & 111 & 68 & 66 & 88 \\
\hline 0 axaca & 1073 & 1043 & 30 & 1564 & 2612 & 1670 & 54 & 354 & 48 & 38 \\
\hline Puebla & 906 & 867 & 39 & 2826 & 2728 & 1996 & 104 & 313 & 67 & 75 \\
\hline Q uerétaro & 281 & 273 & 8 & 743 & 990 & 602 & 30 & 160 & 17 & 21 \\
\hline Q uintana Roo & 191 & 178 & 13 & 413 & 454 & 377 & 28 & 76 & 24 & 14 \\
\hline San Luis Potosí & 470 & 449 & 21 & 1446 & 1280 & 1006 & 44 & 124 & 32 & 33 \\
\hline Sinaloa & 459 & 434 & 25 & 2038 & 1787 & 1328 & 87 & 187 & 43 & 54 \\
\hline Sonora & 376 & 337 & 39 & 2446 & 1725 & 1257 & 94 & 205 & 57 & 66 \\
\hline Tabasco & 576 & 554 & 22 & 1315 & 1484 & 1174 & 57 & 251 & 51 & 33 \\
\hline Tamaulipas & 433 & 397 & 36 & 2682 & 1661 & 1428 & 89 & 123 & 67 & 66 \\
\hline Tlaxcala & 200 & 192 & 8 & 512 & 676 & 406 & 15 & 139 & 12 & 10 \\
\hline Veracruz & 1352 & 1279 & 73 & 4439 & 3881 & 3351 & 176 & 362 & 98 & 108 \\
\hline Yucatán & 329 & 310 & 19 & 1592 & 888 & 789 & 47 & 87 & 34 & 37 \\
\hline Zacatecas & 375 & 363 & 12 & 619 & 1146 & 709 & 26 & 128 & 30 & 20 \\
\hline
\end{tabular}

* Se refiere a laboratorios de análisis clínicos

* Se refiere a gabinetes de radiología

Fuente: Dirección General de Estadística e Informática. Boletín de Información Estadística. Recursos y Servicios, 1997. México, D.F.: D GEl, SSA , 1998;núm. 17, vol. I 


\section{Cuadro II \\ Principales Recursos físicos y materiales Por institución de SALUd. \\ Sistema Nacional de Salud, México, 1997}

Institución

$N$ acional

Población abierta

Secretaría de Salud*

Instituto Mexicano del Seguro Social-Solidaridad

Universitarios

Cruz Roja Mexicana

Instituto $\mathrm{N}$ acional Indigenista

Población derechohabiente

Instituto Mexicano del Seguro Social

Instituto de Seguridad y Servicios Sociales

de los Trabajadores del Estado

Petróleos Mexicanos

Secretaría de la Defensa N acional

Secretaría de Marina

Estatales $^{5}$

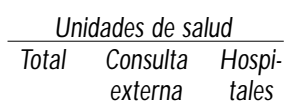

Consultorios

Quiró-

fanos

Salas de expulsión

Labora- Rayos

$17109 \quad 16194 \quad 915$

$915 \quad 76214$

59068

47523

$2599 \quad 6118$

$1675 \quad 1886$

$\begin{array}{llllllllll}13283 & 12828 & 455 & 34974 & 39813 & 25382 & 1137 & 5357 & 925 & 680\end{array}$

$9255 \quad 8890 \quad 365 \quad 31064 \quad 31205$

$3607 \quad 3539$

$\begin{array}{rrrrr}7 & 0 & 7 & 876 & 318\end{array}$

$\begin{array}{rrrrrrrrrr}313 & 299 & 14 & 1170 & 1208 & 648 & 49 & 31 & 14 & 19 \\ 101 & 100 & 1 & 16 & 4 & 106 & 1 & 1 & 1 & 0\end{array}$

* Incluye información del Instituto de Servicios de Salud del D istrito Federal (ISSD F), de la Secretaría de Salud (SSA) y de los institutos nacionales de salud * Se refiere a gabinetes de radiología

§Incluye información del Sistema de Transporte Colectivo-Metro (STC-Metro)

Fuente: Dirección General de Estadística e Informática. Boletín de Información Estadística. Recursos y Servicios, 1997. México, D.F.: D GEl, SSA, 1998;núm. 17, vol. I 


\section{Cuadro III \\ Principales recursos humanos por entidad federativa. Sistema Nacional de Salud, México, 1997}

\begin{tabular}{|c|c|c|c|c|c|c|c|c|c|c|}
\hline \multirow[b]{2}{*}{ Entidad federativa } & \multirow[b]{2}{*}{$\begin{array}{l}\text { Total de } \\
\text { personal }\end{array}$} & \multirow[b]{2}{*}{$\begin{array}{l}\text { Total de } \\
\text { médicos }\end{array}$} & \multicolumn{4}{|c|}{ M édicos en contacto } & \multirow[b]{2}{*}{$\begin{array}{l}\text { M édicos en } \\
\text { otras labores }\end{array}$} & \multicolumn{2}{|c|}{ Paramédicos } & \multirow[b]{2}{*}{$\begin{array}{c}\text { Otro } \\
\text { personal" }\end{array}$} \\
\hline & & & $\begin{array}{l}\text { Gene- } \\
\text { rales }\end{array}$ & $\begin{array}{l}\text { Especia- } \\
\text { listas }\end{array}$ & $\begin{array}{l}\text { En for- } \\
\text { mación* }\end{array}$ & $\begin{array}{l}\text { Odon- } \\
\text { tólogos }\end{array}$ & & $\begin{array}{l}\text { Enfer- } \\
\text { meras }\end{array}$ & $\begin{array}{l}\text { Otros para- } \\
\text { médicos }\end{array}$ & \\
\hline$N$ acional & 506448 & 129031 & 32502 & 40019 & 29086 & 8148 & 19276 & 172294 & 35674 & 169449 \\
\hline A guascalientes & 5649 & 1536 & 336 & 556 & 347 & 74 & 223 & 2005 & 380 & 1728 \\
\hline Baja California & 10867 & 2895 & 743 & 1057 & 408 & 189 & 498 & 3869 & 825 & 3278 \\
\hline Baja California Sur & 3856 & 985 & 309 & 335 & 166 & 56 & 119 & 1317 & 211 & 1343 \\
\hline Campeche & 3963 & 1075 & 396 & 357 & 149 & 67 & 106 & 1264 & 276 & 1348 \\
\hline Coahuila & 15839 & 3760 & 1025 & 1380 & 486 & 206 & 663 & 5818 & 1269 & 4992 \\
\hline Colima & 3411 & 925 & 236 & 335 & 170 & 56 & 128 & 1229 & 234 & 1023 \\
\hline Chiapas & 12510 & 3463 & 1016 & 987 & 859 & 318 & 283 & 4306 & 785 & 3956 \\
\hline Chihuahua & 13592 & 3350 & 1131 & 1009 & 465 & 155 & 590 & 5047 & 1218 & 3977 \\
\hline Distrito Federal & 125798 & 28973 & 4964 & 10054 & 7562 & 1695 & 4698 & 39935 & 8932 & 47958 \\
\hline Durango & 7770 & 2008 & 512 & 626 & 503 & 97 & 270 & 2882 & 510 & 2370 \\
\hline Guanajuato & 15383 & 4209 & 1292 & 1129 & 946 & 229 & 613 & 5542 & 1140 & 4492 \\
\hline Guerrero & 10735 & 2805 & 1016 & 735 & 630 & 159 & 265 & 3908 & 622 & 3400 \\
\hline Hidalgo & 8567 & 2321 & 629 & 582 & 682 & 120 & 308 & 3096 & 425 & 2725 \\
\hline Jalisco & 28926 & 7726 & 1831 & 2467 & 1655 & 424 & 1349 & 10306 & 2350 & 8544 \\
\hline México & 42299 & 10820 & 3270 & 2649 & 2155 & 896 & 1850 & 12660 & 3261 & 15558 \\
\hline Michoacán & 12834 & 3811 & 989 & 1009 & 1068 & 281 & 464 & 4306 & 626 & 4091 \\
\hline Morelos & 7012 & 1794 & 470 & 624 & 347 & 138 & 215 & 2503 & 590 & 2125 \\
\hline$N$ ayarit & 4970 & 1313 & 320 & 349 & 335 & 101 & 208 & 1874 & 293 & 1490 \\
\hline Nuevo León & 24842 & 5837 & 1483 & 2009 & 896 & 280 & 1169 & 9216 & 1968 & 7821 \\
\hline 0 axaca & 11204 & 3223 & 833 & 740 & 1163 & 226 & 261 & 3943 & 542 & 3496 \\
\hline Puebla & 16993 & 4525 & 1066 & 1199 & 1196 & 476 & 588 & 6127 & 956 & 5385 \\
\hline Querétaro & 5894 & 1738 & 419 & 479 & 475 & 149 & 216 & 2128 & 453 & 1575 \\
\hline Q uintana Roo & 3961 & 1061 & 329 & 343 & 135 & 70 & 184 & 1310 & 284 & 1306 \\
\hline San Luis Potosí & 9097 & 2276 & 551 & 694 & 625 & 147 & 259 & 3327 & 661 & 2833 \\
\hline Sinaloa & 13529 & 3437 & 910 & 1118 & 648 & 160 & 601 & 4864 & 1082 & 4146 \\
\hline Sonora & 14034 & 3525 & 849 & 1263 & 713 & 163 & 537 & 4848 & 968 & 4693 \\
\hline Tabasco & 10969 & 3020 & 1018 & 850 & 599 & 289 & 264 & 3615 & 659 & 3675 \\
\hline Tamaulipas & 16162 & 3926 & 1129 & 1395 & 686 & 191 & 525 & 5437 & 1095 & 5704 \\
\hline Tlaxcala & 3553 & 1009 & 272 & 245 & 258 & 99 & 135 & 1185 & 257 & 1102 \\
\hline Veracruz & 28193 & 7877 & 2263 & 2343 & 1689 & 415 & 1167 & 9467 & 1937 & 8912 \\
\hline Yucatán & 8968 & 2398 & 534 & 714 & 654 & 133 & 363 & 3134 & 578 & 2858 \\
\hline Zacatecas & 5068 & 1410 & 361 & 387 & 416 & 89 & 157 & 1826 & 287 & 1545 \\
\hline
\end{tabular}

Fuente: Dirección General de Estadística e Informática. Boletín de Información Estadística. Recursos y Servicios, 1997. México, D.F.: D GEl, SSA , 1998;núm. 17, vol. I 


\section{Cuadro IV \\ Principales recursos humanos por institución de SALUd. Sistema Nacional de Salud, México}

\begin{tabular}{|c|c|c|c|c|c|c|c|c|c|c|}
\hline & & & & Médico & s en conta & & & Paran & nédicos & \\
\hline Institución & $\begin{array}{l}\text { Total de } \\
\text { personal }\end{array}$ & $\begin{array}{l}\text { Total de } \\
\text { médicos }\end{array}$ & $\begin{array}{l}\text { Gene- } \\
\text { rales }\end{array}$ & $\begin{array}{l}\text { Especia- } \\
\text { listas }\end{array}$ & $\begin{array}{l}\text { En for- } \\
\text { mación }{ }^{*}\end{array}$ & $\begin{array}{l}\text { Odon- } \\
\text { tólogos }\end{array}$ & $\begin{array}{l}\text { M édicos en } \\
\text { otras labores }\end{array}$ & $\begin{array}{l}\text { Enfer- } \\
\text { meras }\end{array}$ & $\begin{array}{l}\text { Otros para- } \\
\text { médicos }\end{array}$ & $\begin{array}{c}\text { Otro } \\
\text { personalf }\end{array}$ \\
\hline$N$ acional & 506448 & 129031 & 32502 & 40019 & 29086 & 8148 & 19276 & 172294 & 35674 & 169449 \\
\hline Población abierta & 203024 & 56036 & 11887 & 14602 & 20300 & 4634 & 4613 & 70847 & 4596 & 71545 \\
\hline Secretaría de Salud* & 175799 & 47609 & 10669 & 12782 & 15860 & 4420 & 3878 & 60872 & 3565 & 63753 \\
\hline Instituto Mexicano del Seguro Social-Solidaridad & 17139 & 5419 & 411 & 705 & 3910 & 134 & 259 & 6693 & 368 & 4659 \\
\hline Universitarios & 4586 & 1236 & 33 & 599 & 458 & 12 & 134 & 1547 & 213 & 1590 \\
\hline Cruz Roja Mexicana & 5206 & 1630 & 700 & 516 & 69 & 8 & 337 & 1691 & 370 & 1515 \\
\hline Instituto $\mathrm{N}$ acional Indigenista & 294 & 142 & 74 & 0 & 3 & 60 & 5 & 44 & 80 & 28 \\
\hline Población derechohabiente & 303424 & 72995 & 20615 & 25417 & 8786 & 3514 & 14663 & 101447 & 31078 & 97904 \\
\hline Instituto Mexicano del Seguro Social $\left.\right|^{\ddagger}$ & 209232 & 48658 & 13503 & 14552 & 5435 & 1700 & 13468 & 74681 & 23399 & 62494 \\
\hline Instituto de Seguridad y Servicios Sociales & & & & & & & & & & \\
\hline de los Trabajadores del Estado & 61566 & 16487 & 4564 & 7403 & 2749 & 946 & 825 & 18460 & 1919 & 24700 \\
\hline Petróleos Mexicanos & 10704 & 2405 & 927 & 1241 & 0 & 120 & 117 & 2656 & 999 & 4644 \\
\hline Secretaría de la D efensa $\mathrm{N}$ acional & 9930 & 1829 & 482 & 569 & 266 & 472 & 40 & 2401 & 4361 & 1339 \\
\hline Secretaría de Marina & 3208 & 832 & 240 & 389 & 58 & 107 & 38 & 913 & 134 & 1329 \\
\hline Estatales $^{\S}$ & 8784 & 2784 & 899 & 1263 & 278 & 169 & 175 & 2336 & 266 & \\
\hline
\end{tabular}

* Incluye información del ISSD F, de la SSA y de los institutos nacionales de salud

₹ No se incluye a 160 médicos, 19 paramédicos de enfermería, 227 auxiliares de diagnóstico y tratamiento,145 administrativos y 891 de otro personal, que laboran en oficinas centrales del Instituto Mexicano del Seguro Social

§Incluye información del STC-Metro

\# Incluye residentes y pasantes

f Incluye auxiliares de diagnóstico y tratamiento, personal administrativo y otro personal

Fuente: Dirección G eneral de Estadística e Informática. Boletín de Información Estadística. Recursos y Servicios, 1997. México, D.F.: D GEl, SSA, 1998;núm. 17, vol. I 


\section{Principales servicios otorgados por entidad federativa. Sistema Nacional de Salud, México, 1997}

\begin{tabular}{|c|c|c|c|c|c|c|c|c|c|c|}
\hline \multirow[b]{2}{*}{ Entidad federativa } & \multicolumn{4}{|c|}{ Consultas } & \multicolumn{2}{|c|}{ Partos } & \multirow[b]{2}{*}{ Egresos } & \multirow[b]{2}{*}{$\begin{array}{c}\text { Intervenciones } \\
\text { quirúrgicas }\end{array}$} & \multirow[b]{2}{*}{$\begin{array}{l}\text { Días de } \\
\text { estancia }\end{array}$} & \multirow[b]{2}{*}{$\begin{array}{c}\text { Usuarias } \\
\text { activas }\end{array}$} \\
\hline & $\begin{array}{l}\text { Gene- } \\
\text { rales }\end{array}$ & $\begin{array}{l}\text { Especiali- } \\
\text { zadas }\end{array}$ & $\begin{array}{l}\text { Odonto- } \\
\text { lógicas }\end{array}$ & $\begin{array}{l}\text { Urgen- } \\
\text { cias }\end{array}$ & Total & $\begin{array}{c}\text { Cesáreas } \\
\%\end{array}$ & & & & \\
\hline $\mathrm{N}$ acional & 11819689 & 33200750 & 11222371 & 22206108 & 1446706 & 30.1 & 4633789 & 2584986 & 18266486 & 8650009 \\
\hline Aguascalientes & 1468168 & 332612 & 110680 & 253448 & 20889 & 29.3 & 53586 & 31575 & 205542 & 73657 \\
\hline Baja California & 2814679 & 792496 & 234658 & 656164 & 42438 & 32.7 & 106112 & 68292 & 424227 & 203460 \\
\hline Baja California Sur & 955729 & 253345 & 85430 & 192757 & 8946 & 31.9 & 31969 & 18069 & 116616 & 47645 \\
\hline Campeche & 1211371 & 274128 & 91774 & 239683 & 10841 & 30.8 & 31449 & 18352 & 112414 & 64119 \\
\hline Coahuila & 4753099 & 1057036 & 350581 & 1017268 & 50374 & 31.2 & 221582 & 95537 & 647115 & 241979 \\
\hline Colima & 947228 & 215833 & 66970 & 191814 & 10464 & 32.4 & 32494 & 20618 & 97414 & 66722 \\
\hline Chiapas & 4335561 & 526956 & 362342 & 452419 & 30200 & 27.1 & 110965 & 65860 & 392023 & 330585 \\
\hline Chihuahua & 4834285 & 899751 & 266030 & 630051 & 48513 & 27.0 & 235274 & 84946 & 481985 & 298720 \\
\hline Distrito Federal & 652721 & 8662737 & 1932218 & 3559023 & 168621 & 37.3 & 705725 & 423597 & 4129430 & 996909 \\
\hline Durango & 2847068 & 479372 & 154747 & 445777 & 27220 & 27.0 & 78304 & 46806 & 301783 & 157074 \\
\hline Guanajuato & 5296816 & 1096220 & 373191 & 655761 & 69889 & 27.6 & 171664 & 109795 & 682113 & 297837 \\
\hline Guerrero & 3899241 & 580369 & 208705 & 432173 & 31288 & 24.2 & 169632 & 57111 & 289137 & 256558 \\
\hline Hidalgo & 2949778 & 423206 & 214212 & 384640 & 32802 & 25.7 & 83839 & 39320 & 352888 & 210555 \\
\hline Jalisco & 8556525 & 2429390 & 581109 & 1709025 & 109546 & 29.2 & 336769 & 193801 & 1204465 & 458802 \\
\hline México & 15914210 & 1838514 & 1320601 & 1634778 & 134652 & 27.7 & 302741 & 199971 & 1396132 & 1148922 \\
\hline Michoacán & 4937025 & 741035 & 390874 & 523626 & 48491 & 25.1 & 193228 & 70378 & 465183 & 338802 \\
\hline Morelos & 2124386 & 400348 & 196419 & 445929 & 19909 & 32.3 & 58070 & 41155 & 215013 & 123662 \\
\hline$N$ ayarit & 1804187 & 319636 & 137227 & 158409 & 15302 & 26.5 & 46527 & 26381 & 145958 & 110993 \\
\hline Nuevo León & 6909503 & 1835980 & 479506 & 1700568 & 65704 & 40.9 & 221959 & 155370 & 1088694 & 350786 \\
\hline 0 axaca & 3990369 & 476484 & 316804 & 273142 & 39779 & 27.9 & 96636 & 51906 & 397427 & 244727 \\
\hline Puebla & 5312754 & 1058372 & 498027 & 659919 & 52573 & 27.5 & 149777 & 94471 & 654095 & 395380 \\
\hline Q uerétaro & 762698 & 345162 & 164356 & 306373 & 26644 & 29.8 & 48938 & 36942 & 166853 & 113299 \\
\hline Q uintana Roo & 1158236 & 201183 & 90823 & 279631 & 14187 & 32.4 & 32545 & 21416 & 101452 & 57252 \\
\hline San Luis Potosí & 3154199 & 567612 & 235547 & 462388 & 36284 & 21.5 & 100255 & 54787 & 408010 & 194024 \\
\hline Sinaloa & 4905988 & 935841 & 324355 & 702004 & 46689 & 29.5 & 141714 & 86449 & 549446 & 290642 \\
\hline Sonora & 3748114 & 1061201 & 254166 & 757444 & 43334 & 30.0 & 134167 & 72819 & 598850 & 186189 \\
\hline Tabasco & 3814707 & 750929 & 335320 & 471853 & 29184 & 29.1 & 89224 & 56904 & 326959 & 182060 \\
\hline Tamaulipas & 4779555 & 1451766 & 295762 & 780705 & 48927 & 33.5 & 151606 & 81811 & 614582 & 235574 \\
\hline Tlaxcala & 1470336 & 184806 & 120629 & 191779 & 14154 & 28.3 & 32469 & 19640 & 94790 & 79778 \\
\hline Veracruz & 9665476 & 2095105 & 670469 & 1322159 & 84998 & 30.1 & 323693 & 159884 & 1055852 & 633835 \\
\hline Yucatán & 3707597 & 630425 & 212149 & 440295 & 26345 & 31.6 & 80454 & 48911 & 377381 & 119320 \\
\hline Zacatecas & 2138080 & 282900 & 146690 & 275103 & 24517 & 22.1 & 60422 & 32112 & 172657 & 140142 \\
\hline
\end{tabular}

Fuente: Dirección General de Estadística e Informática. Boletín de Información Estadística. Recursos y Servicios, 1997. México, D.F:: D GEl, SSA, 1998;núm. 17, vol. I 


\section{Cuadro VI}

Principales servicios otorgados POR INSTITUCión De SALUd. Sistema Nacional de Salud, México, 1997

\begin{tabular}{|c|c|c|c|c|c|c|c|c|c|c|}
\hline \multirow[b]{2}{*}{ Institución } & \multicolumn{4}{|c|}{ Consultas } & \multicolumn{2}{|c|}{ Partos } & \multirow[b]{2}{*}{ Egresos } & \multirow[b]{2}{*}{$\begin{array}{l}\text { Intervenciones } \\
\text { quirúrgicas }\end{array}$} & \multirow[b]{2}{*}{$\begin{array}{l}\text { S Días de } \\
\text { estancia }\end{array}$} & \multirow[b]{2}{*}{$\begin{array}{c}\text { Usuarias } \\
\text { activas }\end{array}$} \\
\hline & $\begin{array}{l}\text { Gene- } \\
\text { rales }\end{array}$ & $\begin{array}{c}\text { Especiali- } \\
\text { zadas }\end{array}$ & $\begin{array}{l}\text { Odonto- } \\
\text { lógicas }\end{array}$ & $\begin{array}{l}\text { Urgen- } \\
\text { cias }\end{array}$ & Total & $\begin{array}{c}\% \\
\text { cesáreas }\end{array}$ & & & & \\
\hline $\mathrm{N}$ acional & 141819689 & 33200750 & 11222371 & 22206108 & 1446706 & 30.1 & 4633789 & 2584986 & 18266486 & 8650009 \\
\hline Población abierta & 50706710 & 8196394 & 4096379 & 4766523 & 689419 & 23.1 & 2123990 & 866129 & 6737107 & 3258452 \\
\hline Secretaría de Salud* & 38852774 & 7470761 & 3656243 & 4139525 & 556443 & 24.2 & 1474244 & 722537 & 5829962 & 2387573 \\
\hline \multicolumn{11}{|l|}{ Instituto Mexicano del Seguro } \\
\hline Social-Solidaridad & 10933850 & 349327 & 429328 & 573853 & 123151 & 16.9 & 223408 & 115473 & 730774 & 868857 \\
\hline Universitarios & 98044 & 269437 & 6163 & 53145 & 8877 & 43.7 & 37925 & 18363 & 173049 & 1771 \\
\hline Cruz Roja & 705467 & 99260 & 0 & 0 & 714 & ND & 387471 & 9521 & ND & ND \\
\hline Instituto $\mathrm{N}$ acional Indigenista & 116575 & 7609 & 4645 & 0 & 234 & ND & 942 & 235 & 3322 & 251 \\
\hline Población derechohabiente & 91112979 & 25004356 & 7125992 & 17439585 & 757287 & 36.4 & 2509799 & 1718857 & 11529379 & 5391557 \\
\hline Instituto Mexicano del Seguro Social & 68784211 & 14883012 & 4559944 & 15042506 & 657349 & 35.2 & 1891201 & 1349830 & 8963168 & 4327995 \\
\hline \multicolumn{11}{|c|}{ Instituto de Seguridad y Servicios Sociales } \\
\hline de los Trabajadores del Estado & 15553399 & 5509376 & 1379373 & 826431 & 63455 & 48.1 & 360369 & 253270 & 1513521 & 846286 \\
\hline Petróleos Mexicanos & 2563354 & 1983460 & 310669 & 739035 & 6168 & 45.1 & 73246 & 30768 & 295980 & 70256 \\
\hline Secretaría de la D efensa $\mathrm{N}$ acional & 1089882 & 908712 & 441892 & 130942 & 8860 & 22.3 & 69291 & 24005 & 398753 & 38437 \\
\hline Secretaría de Marina & 279592 & 438698 & 112668 & 86839 & 3912 & 39.4 & 25785 & 9861 & 97834 & 7896 \\
\hline Estatales ${ }^{\ddagger}$ & 2842541 & 1281098 & 321446 & 613832 & 17543 & 41.8 & 89907 & 51123 & 260123 & 100687 \\
\hline
\end{tabular}

* Incluye información del ISSDF, de la SSA y de los institutos nacionales de salud

₹Incluye informacion del STC -Metro

N D: no disponible

Fuente: Dirección General de Estadística e Informática. Boletín de Información Estadística. Recursos y Servicios, 1997. México, D.F.: D GEl, SSA, 1998;núm. 17, vol. I 


\section{Cuadro VII \\ Coberturas de vacunación por entidad federativa. Sistema Nacional de Salud, México, 1997}

\begin{tabular}{|c|c|c|c|c|c|c|c|c|c|c|}
\hline \multirow[b]{2}{*}{ Entidad federativa } & \multicolumn{5}{|c|}{ Niños de 1 año } & \multicolumn{5}{|c|}{ Niños de 1 a 4 años } \\
\hline & Esquema básico & Sabin & DPT & Antisarampión & $\mathrm{BCG}$ & Esquema básico & Sabin & DPT & Antisarampión & $\mathrm{BCG}$ \\
\hline $\mathrm{N}$ acional & 89.6 & 95.3 & 95.1 & 90.5 & 99.1 & 96.8 & 98.3 & 98.2 & 97.2 & 99.6 \\
\hline Aguascalientes & 94.7 & 97.7 & 97.1 & 95.7 & 99.5 & 98.4 & 99.3 & 99.1 & 98.7 & 99.9 \\
\hline Baja California & 73.9 & 88.9 & 88.2 & 74.8 & 98.5 & 92.9 & 96.9 & 96.7 & 93.2 & 99.4 \\
\hline Baja California Sur & 80.8 & 95.2 & 95.1 & 81.2 & 99.3 & 94.8 & 98.5 & 98.4 & 94.9 & 99.6 \\
\hline Campeche & 99.7 & 99.9 & 99.9 & 99.7 & 100.0 & 99.9 & 100.0 & 100.0 & 99.9 & 100.0 \\
\hline Coahuila & 93.0 & 98.0 & 97.9 & 93.6 & 99.8 & 98.3 & 99.4 & 99.4 & 98.5 & 99.9 \\
\hline Colima & 93.9 & 98.4 & 98.4 & 94.3 & 99.8 & 98.5 & 99.5 & 99.5 & 98.6 & 99.9 \\
\hline Chiapas & 82.1 & 89.4 & 88.7 & 86.3 & 98.4 & 93.2 & 95.2 & 94.8 & 95.6 & 99.1 \\
\hline Chihuahua & 85.9 & 91.8 & 91.6 & 87.1 & 99.0 & 95.7 & 97.2 & 97.0 & 96.4 & 99.5 \\
\hline Distrito Federal & 76.2 & 86.5 & 86.2 & 77.7 & 96.8 & 91.6 & 94.7 & 94.5 & 92.5 & 98.1 \\
\hline Durango & 89.8 & 94.4 & 94.3 & 91.2 & 99.6 & 97.0 & 98.2 & 98.1 & 97.7 & 99.8 \\
\hline Guanajuato & 87.9 & 93.2 & 92.8 & 89.3 & 98.5 & 95.8 & 97.4 & 97.1 & 96.4 & 99.1 \\
\hline Guerrero & 95.8 & 98.4 & 98.3 & 96.4 & 99.8 & 98.8 & 99.4 & 99.4 & 99.1 & 99.9 \\
\hline Hidalgo & 97.4 & 99.7 & 99.7 & 97.5 & 99.9 & 99.4 & 99.9 & 99.9 & 99.4 & 100.0 \\
\hline Jalisco & 91.4 & 96.0 & 95.8 & 91.7 & 99.9 & 97.1 & 98.5 & 98.5 & 97.2 & 99.9 \\
\hline México & 86.3 & 93.3 & 93.0 & 87.4 & 97.9 & 96.1 & 97.9 & 97.8 & 96.6 & 99.3 \\
\hline Michoacán & 91.8 & 96.6 & 96.5 & 93.1 & 99.7 & 97.4 & 98.7 & 98.6 & 98.0 & 99.8 \\
\hline Morelos & 91.3 & 98.7 & 98.6 & 91.6 & 99.9 & 97.8 & 99.6 & 99.6 & 97.9 & 100.0 \\
\hline $\mathrm{N}$ ayarit & 97.3 & 99.8 & 99.8 & 97.4 & 100.0 & 99.4 & 100.0 & 100.0 & 99.4 & 100.0 \\
\hline Nuevo León & 96.3 & 99.2 & 99.2 & 97.0 & 99.2 & 98.8 & 99.7 & 99.7 & 99.3 & 99.5 \\
\hline 0 aхаса & 88.2 & 95.8 & 95.5 & 89.6 & 99.5 & 96.5 & 98.5 & 98.2 & 97.2 & 99.7 \\
\hline Puebla & 90.5 & 94.5 & 94.4 & 91.6 & 98.8 & 96.9 & 97.9 & 97.9 & 97.4 & 99.5 \\
\hline Querétaro & 85.4 & 97.2 & 97.2 & 85.8 & 99.9 & 96.0 & 99.0 & 99.0 & 96.2 & 99.9 \\
\hline Q uintana Roo & 96.0 & 98.9 & 98.9 & 96.1 & 99.9 & 98.6 & 99.3 & 99.3 & 98.6 & 99.9 \\
\hline San Luis Potosí & 87.8 & 93.4 & 93.2 & 88.7 & 98.7 & 96.9 & 98.2 & 98.2 & 97.2 & 99.5 \\
\hline Sinaloa & 94.8 & 99.1 & 99.1 & 94.9 & 99.9 & 98.7 & 99.7 & 99.7 & 98.7 & 100.0 \\
\hline Sonora & 88.4 & 96.7 & 96.6 & 88.7 & 99.7 & 97.2 & 99.1 & 99.1 & 97.3 & 99.9 \\
\hline Tabasco & 97.6 & 99.8 & 99.8 & 97.6 & 100.0 & 99.4 & 99.9 & 99.9 & 99.4 & 100.0 \\
\hline Tamaulipas & 92.8 & 97.6 & 97.5 & 93.2 & 99.6 & 98.4 & 99.5 & 99.4 & 98.5 & 99.9 \\
\hline Tlaxcala & 96.2 & 99.0 & 98.9 & 96.4 & 99.9 & 99.0 & 99.7 & 99.6 & 99.1 & 99.9 \\
\hline Veracruz & 93.2 & 97.5 & 97.4 & 93.7 & 99.8 & 98.2 & 99.2 & 99.2 & 98.4 & 99.9 \\
\hline Yucatán & 94.0 & 98.9 & 98.8 & 94.1 & 99.8 & 98.5 & 99.6 & 99.6 & 98.6 & 99.9 \\
\hline Zacatecas & 98.3 & 99.7 & 99.6 & 98.4 & 100.0 & 99.6 & 99.9 & 99.9 & 99.6 & 100.0 \\
\hline
\end{tabular}

Fuente: SSA/C onsejo N acional de Vacunación. México, 1998 


\section{Cuadro VIII}

Principales indicadores Sobre ReCURSOS Y SERVICIOS POR ENTIDAD federativa.

\section{Sistema Nacional de Salud, México 1997}

$\begin{array}{ccccccccccc} & \text { Camas por } & \text { Médicos por } & \text { Enfermeras } & \text { Enfermeras } & \text { Consultorios } & \text { Partos por } & \text { Invertenciones } & \text { Consultas } & \text { Usuarias } & \text { Ocupación } \\ \text { Entidad federativa } & 100000 & 100000 & \text { por } & \text { por } & \text { por } 100000 & 1000 & \text { quirúrgicas por } & \text { diarias por por } 1000 \text { hospitalaria } \\ & \text { habitantes } & \text { habitantes } & \text { médico } & \text { cama } & \text { habitantes } & \text { egresos } & \text { quirófano } & \text { médico* } & \text { MEF } & (\%)\end{array}$

\begin{tabular}{|c|c|c|c|c|c|c|c|c|c|c|}
\hline N acional ${ }^{\ddagger}$ & 80.5 & 115.9 & 1.6 & 2.3 & 50.2 & 312.2 & 2.7 & 8.6 & 340.3 & 69.6 \\
\hline Aguascalientes & 92.1 & 149.1 & 1.5 & 2.5 & 47.8 & 389.8 & 3.1 & 7.5 & 302.2 & 76.0 \\
\hline Baja California & 66.4 & 105.8 & 1.6 & 2.6 & 36.6 & 399.9 & 3.2 & 8.5 & 314.8 & 75.9 \\
\hline Baja California Sur & 143.2 & 211.9 & 1.5 & 2.3 & 83.7 & 279.8 & 1.8 & 7.8 & 423.9 & 56.0 \\
\hline Campeche & 89.8 & 146.5 & 1.3 & 2.1 & 68.6 & 344.7 & 1.9 & 8.5 & 370.0 & 55.6 \\
\hline Coahuila & 110.2 & 137.7 & 1.9 & 2.3 & 59.1 & 227.3 & 2.9 & 10.5 & 389.8 & 72.9 \\
\hline Colima & 95.5 & 163.4 & 1.5 & 2.6 & 74.6 & 322.1 & 3.8 & 8.1 & 500.3 & 60.8 \\
\hline Chiapas & 42.1 & 82.6 & 1.4 & 2.7 & 51.0 & 389.3 & 2.6 & 8.1 & 334.4 & 70.0 \\
\hline Chihuahua & 74.6 & 94.2 & 1.8 & 2.3 & 44.1 & 206.2 & 3.3 & 10.9 & 373.2 & 80.1 \\
\hline Distrito Federal & 210.3 & 303.4 & 1.6 & 2.4 & 93.2 & 238.9 & 2.1 & 5.6 & 408.2 & 70.1 \\
\hline Durango & 81.4 & 120.2 & 1.7 & 2.5 & 59.2 & 347.6 & 3.6 & 10.3 & 425.1 & 76.2 \\
\hline Guanajuato & 57.5 & 78.4 & 1.5 & 2.1 & 31.7 & 407.1 & 3.7 & 9.4 & 244.6 & 69.1 \\
\hline Guerrero & 48.9 & 86.8 & 1.5 & 2.7 & 53.4 & 184.4 & 2.7 & 9.2 & 353.7 & 61.5 \\
\hline Hidalgo & 60.2 & 92.9 & 1.5 & 2.4 & 51.7 & 391.2 & 3.4 & 9.0 & 376.6 & 80.2 \\
\hline Jalisco & 92.5 & 99.5 & 1.6 & 1.7 & 44.3 & 325.3 & 2.7 & 9.5 & 272.3 & 57.9 \\
\hline México & 53.4 & 69.5 & 1.4 & 1.8 & 33.0 & 444.8 & 3.3 & 10.5 & 331.3 & 64.8 \\
\hline Michoacán & 50.7 & 85.7 & 1.3 & 2.2 & 41.5 & 251.0 & 2.5 & 9.0 & 343.4 & 69.8 \\
\hline Morelos & 55.8 & 110.4 & 1.6 & 3.1 & 44.3 & 342.8 & 3.6 & 9.1 & 317.2 & 81.8 \\
\hline $\mathrm{N}$ ayarit & 74.2 & 122.0 & 1.7 & 2.8 & 65.8 & 328.9 & 2.4 & 10.0 & 484.1 & 63.5 \\
\hline Nuevo León & 102.9 & 130.1 & 2.0 & 2.5 & 56.8 & 296.0 & 3.8 & 10.6 & 343.0 & 82.8 \\
\hline 0 axaca & 45.2 & 85.6 & 1.3 & 2.5 & 48.3 & 411.6 & 2.6 & 7.8 & 287.7 & 69.2 \\
\hline Puebla & 56.6 & 78.9 & 1.6 & 2.2 & 40.0 & 351.0 & 2.5 & 8.7 & 312.6 & 68.3 \\
\hline Q uerétaro & 57.1 & 116.9 & 1.4 & 2.9 & 46.2 & 544.4 & 3.4 & 7.7 & 329.6 & 70.1 \\
\hline Q uintana Roo & 55.8 & 118.6 & 1.5 & 3.2 & 51.0 & 435.9 & 2.1 & 9.0 & 286.0 & 70.6 \\
\hline San Luis Potosí & 63.4 & 88.4 & 1.6 & 2.3 & 44.1 & 361.9 & 3.4 & 10.0 & 334.2 & 76.7 \\
\hline Sinaloa & 83.4 & 116.1 & 1.7 & 2.4 & 54.4 & 329.5 & 2.7 & 11.0 & 440.5 & 77.6 \\
\hline Sonora & 115.1 & 140.6 & 1.6 & 2.0 & 59.1 & 323.0 & 2.1 & 8.9 & 319.3 & 70.8 \\
\hline Tabasco & 74.5 & 156.2 & 1.3 & 2.7 & 66.5 & 327.1 & 2.7 & 8.9 & 380.3 & 77.3 \\
\hline Tamaulipas & 103.1 & 130.7 & 1.6 & 2.0 & 54.9 & 322.7 & 2.5 & 9.8 & 321.5 & 64.8 \\
\hline Tlaxcala & 55.1 & 94.0 & 1.4 & 2.3 & 43.7 & 435.9 & 3.6 & 10.2 & 325.6 & 52.6 \\
\hline Veracruz & 61.9 & 93.6 & 1.4 & 2.1 & 46.7 & 262.6 & 2.5 & 9.3 & 331.9 & 66.9 \\
\hline Yucatán & 102.0 & 130.4 & 1.5 & 2.0 & 50.5 & 327.5 & 2.9 & 11.1 & 289.3 & 65.7 \\
\hline Zacatecas & 45.4 & 91.8 & 1.5 & 2.9 & 52.0 & 405.8 & 3.4 & 10.3 & 410.4 & 81.8 \\
\hline
\end{tabular}

* Se refiere a médicos en contacto con el paciente

₹ Para el cálculo de los indicadores se utilizó la población estimada por el Consejo N acional de Población

MEF: mujeres en edad fértil

Fuente: Dirección General de Estadística e Informática. Boletín de Información Estadística. Recursos y Servicios, 1997. México, D.F.: D GEl, SSA, 1998;núm. 17, vol. I 


\section{Cuadro IX \\ Principales indicadores sobre ReCURSOS Y SERVICIOS POR INSTITUCIÓN DE SALUd. Sistema Nacional de Salud, México, 1997}

\begin{tabular}{|c|c|c|c|c|c|c|c|c|c|c|}
\hline Institución & $\begin{array}{c}\text { Camas por } \\
100000 \\
\text { habitantes }\end{array}$ & $\begin{array}{l}\text { M édicos por } \\
100000 \\
\text { habitantes }\end{array}$ & $\begin{array}{c}\text { Enfermeras } \\
\text { por } \\
\text { médico }\end{array}$ & $\begin{array}{c}\text { Enfermeras } \\
\text { por } \\
\text { cama }\end{array}$ & $\begin{array}{c}\text { Consultorios } \\
\text { por } 100000 \\
\text { habitantes }\end{array}$ & $\begin{array}{l}\text { Partos por } \\
1000 \\
\text { egresos }\end{array}$ & $\begin{array}{l}\text { Invertenciones } \\
\text { quirúrgicas por } \\
\text { quirófano }\end{array}$ & $\begin{array}{l}\text { Consultas } \\
\text { diarias por } \\
\text { médico* }\end{array}$ & $\begin{array}{c}\text { Usuarias } \\
\text { por } 1000 \\
\text { MEF }\end{array}$ & $\begin{array}{c}\text { Ocupación } \\
\text { hospitalaria } \\
\%\end{array}$ \\
\hline N acional ${ }^{\ddagger}$ & 80.5 & 115.9 & 1.6 & 2.3 & 50.2 & 312.2 & 2.7 & 8.6 & 340.3 & 69.6 \\
\hline Población abierta & 75.4 & 110.9 & 1.4 & 2.0 & 54.7 & 324.1 & 2.1 & 6.0 & 318.9 & 59.1 \\
\hline Secretaría de Salud ${ }^{\S}$ & 87.6 & 123.3 & 1.4 & 2.0 & 56.7 & 377.4 & 2.0 & 5.6 & 334.6 & 59.5 \\
\hline \multicolumn{11}{|l|}{ Instituto Mexicano del Seguro } \\
\hline Social-Solidaridad & 17.0 & 47.3 & 1.3 & 3.6 & 38.4 & 551.2 & 4.7 & 10.8 & 352.9 & 93.5 \\
\hline 0 tras $^{\#}$ & 5.8 & 7.1 & 1.3 & 1.6 & 3.1 & 20.8 & 1.0 & 2.4 & 0.2 & 23.3 \\
\hline Población derechohabiente & 80.2 & 113.4 & 1.7 & 2.5 & 43.0 & 301.7 & 3.2 & 11.0 & 595.9 & 78.4 \\
\hline Instituto Mexicano del Seguro Social & 71.5 & 89.2 & 2.1 & 2.6 & 33.6 & 347.6 & 3.9 & 13.3 & 645.1 & 87.0 \\
\hline \multicolumn{11}{|c|}{ Instituto de Seguridad y Servicios Sociales } \\
\hline de los Trabajadores del Estado & 72.0 & 165.3 & 1.2 & 2.7 & 53.3 & 176.1 & 2.5 & 6.8 & 493.4 & 73.0 \\
\hline Petróleos Mexicanos & 179.5 & 383.2 & 1.2 & 2.5 & 242.3 & 84.2 & 1.4 & 11.1 & 460.6 & 68.2 \\
\hline Secretaría de la D efensa N acional & 700.7 & 391.7 & 1.3 & 0.8 & 241.5 & 127.9 & 0.9 & 6.5 & 391.9 & 34.1 \\
\hline Secretaría de Marina & 388.1 & 431.6 & 1.1 & 1.3 & 207.1 & 151.7 & 0.7 & 5.3 & 172.4 & 38.3 \\
\hline Estatalesf & 95.4 & 206.8 & 0.9 & 1.9 & 71.6 & 195.1 & 1.9 & 8.8 & 308.2 & 58.9 \\
\hline
\end{tabular}

* Se refiere a médicos en contacto con el paciente

₹ Para el cálculo del indicador nacional se utilizó la población estimada por el Consejo N acional de Población; en el caso de las instituciones, las poblaciones de responsabilidad (legal y/o potencial)

$\S$ Incluye información del ISSD F, de la SSA y de los institutos nacionales de salud

*Incluye información de la Cruz Roja, del Instituto N acional Indigenista y Universidades

f Incluye informacion del STC-Metro

MEF: mujeres en edad fértil

Fuente: Dirección General de Estadística e Informática. Boletín de Información Estadística. Recursos y Servicios, 1997. México, D.F:: D GEl, SSA, 1998;núm. 17 , vol. I 